\title{
Small Farm Food Safety, Fresh Produce, Part 3: What's Wrong with this Picture?1
}

Brian Lapinski, Amy Simonne and M.E. Swisher ${ }^{2}$

Time Required: 10 minutes

\section{Materials for Trainer}

Three video clips for exercise "What's Wrong With This Picture"--all included on the DVD.*

\section{Advance Preparation for Trainer}

- Review "Guide to Minimize Microbial Food Safety Hazards for Fresh Fruits and Vegetables," U.S. Dept. of Health and Human Services, Food and Drug Administration, Center for Food Safety and Applied Nutrition, October 1998.

- Preview the video clips and our suggestions of the problems that are illustrated by them.

\section{Materials for Participants}

- None

\section{Objectives}

- Application objective
Participants will be able to identify a number of poor food safety practices on the farm.

\section{- Learning objective}

Participants will increase their knowledge of possible contamination points in a farm operation.

\section{Procedure}

This activity uses three video clips to graphically demonstrate some of the poor food safety practices that can occur on farms. The purpose of the exercise is to enhance participants' ability to identify potential hazardous practices and to get them to think about the kinds of things that occur on their own farms.

- Tell participants to take notes as they view the video clips.

- Before showing the video clips, tell participants that they should identify and write down conditions, situations and activities that increase the risk of microbial contamination.

1. This document is FCS8844, one of a series of the Family Youth and Community Sciences Department, Florida Cooperative Extension Service, Institute of Food and Agricultural Sciences, University of Florida. Original publication date October 5, 2007. Visit the EDIS Web Site at http://edis.ifas.ufl.edu.

2. Brian Lapinski, graduate student, Amy Simonne, associate professor and M.E. Swisher, associate professor, Department of Family, Youth and Community Sciences, Institute of Food and Agricultural Sciences, University of Florida, Gainesville, 32611.

The Institute of Food and Agricultural Sciences (IFAS) is an Equal Opportunity Institution authorized to provide research, educational information and other services only to individuals and institutions that function with non-discrimination with respect to race, creed, color, religion, age, disability, sex, sexual orientation, marital status, national origin, political opinions or affiliations. U.S. Department of Agriculture, Cooperative Extension Service, University of Florida, IFAS, Florida A. \& M. University Cooperative Extension Program, and Boards of County Commissioners Cooperating. Larry Arrington, Dean 
- Ask the participants to identify the conditions, situations and activities that pose threats of contamination. Continue the discussion until all of the points that we list (see below) are mentioned. If participants fail to mention some of them, do so yourself.

- Discuss each clip immediately after viewing it.

\section{Key Points to Make}

\section{Clip 1: In the Shed}

- The first and possibly the biggest mistake is that there is no initial teaching or training at the beginning of the scene. The character who rinsed the lettuce seemed uninformed about what he was doing and he received very little instruction.

- The rag that he used is visibly dirty and unhygienic. Likewise, the bin that he uses to store the clean lettuce is dirty. Wiping it with a wet, dirty rag does not clean it adequately.

- The worker is coughing. He might be ill and he should be not be working with fresh produce.

- The worker drops some lettuce and then places it in the bin without rewashing, a clear contamination threat.

\section{Clip 2: In the Truck}

- Using the same vehicle to haul manure and fresh produce creates an unnecessary risk for microbial contamination.

- Storing gasoline, pesticides and other chemicals near fresh produce, while not a major risk for microbial contamination, could create toxic contamination.

- The interaction of animals with fresh produce creates a contamination risk, even if the animal is a pet. Whenever possible, animals should be kept out of fields, as well as processing and transport locations.

\section{Clip 3: In the Field}

- The farmer says that the buckets are dirty and that they have been left out for a couple days. Bins should be stored under cover and kept clean to avoid exposure to animal wastes or other sources of contamination.

- The worker's coughing is intense. He may well contaminate the produce.

- The discussion about an open cut on the worker's hand that needs bandaging indicates a high potential for contamination.

- The lack of a convenient bathroom facility forces the worker to go near the field, which is unsanitary. There is no way for him to wash his hands afterward.

To obtain copies of the DVD that accompanies this publication, please contact the IFAS Extension Bookstore at 1-800-226-1764 or order online at www.ifasbooks.com. 